\title{
Editorial
}

\section{Alternative Cementitious Materials and Their Composites}

\author{
K. Pimraksa $\mathbb{D}^{1},{ }^{1}$ P. Chindaprasirt $\mathbb{D},^{2}$ J. Sanjayan, ${ }^{3}$ and T.-C. Ling $\mathbb{D}^{4}$ \\ ${ }^{1}$ Department of Industrial Chemistry, Faculty of Science, Chiang Mai University, Chiang Mai 50200, Thailand \\ ${ }^{2}$ Sustainable Infrastructure Research and Development Center, Khon Kaen University, Khon Kaen 40002, Thailand \\ ${ }^{3}$ Center for Sustainable Infrastructure, Faculty of Science Engineering and Technology, Swinburne University of Technology, \\ Hawthorn, VIC 3122, Australia \\ ${ }^{4}$ College of Civil Engineering, Hunan University, Hunan 410082, China
}

Correspondence should be addressed to K. Pimraksa; kedsarin.p@cmu.ac.th

Received 28 January 2018; Accepted 28 January 2018; Published 27 February 2018

Copyright (๑) $2018 \mathrm{~K}$. Pimraksa et al. This is an open access article distributed under the Creative Commons Attribution License, which permits unrestricted use, distribution, and reproduction in any medium, provided the original work is properly cited.

Research and development of alternative cementitious materials as well as supplementary cementing materials (SCMs) become mandatory for construction industry to manage global warming as well as energy scarcity due to huge energy consumptions and greenhouse gas emissions entailed by the conventional cement technology. The improvement in durability of materials is inevitably aimed to be achieved for resource efficiency and safety factor. Researchers are trying to replace Portland cement (PC) with SCMs and low-temperature cementitious materials such as special cements and geopolymeric binders. Besides using alternative cements and SCMs instead of pure Portland cement, their composites with other inorganic materials can work as smart building materials and work for environmental aspects. In this special issue on alternative cementitious materials and their composites, we have invited a few papers that address such issues.

The first paper of this special issue addresses the immobilization of harmful $\mathrm{Pb}$ using alkali-activated materials made of industrial wastes, blast furnace slag (BFS) and coal fly ash. The $\mathrm{Pb}$ immobilization was accomplished at $99 \%$. The best recipe for $\mathrm{Pb}$ solidification was alkali-activated BFS blended with sand, when compared to pure BFS and pure fly ash systems. This was due to the lowest porosity of the sandblended system. The high dosage of $\mathrm{Pb}$ lowered the strength of materials. The second paper proposed the use of natural SCMs such as volcanic rock (scoria) and limestone for economic benefit and early-strength and durability improvements, respectively. The accelerated strength performance was due to the acceleration in precipitation of hydration products when limestone powders were added. The combination of limestone and volcanic scoria created the best environment for $\mathrm{H}_{2} \mathrm{SO}_{4}$ protection due to many reasons: calcium hydroxide reduction, gypsum formation, and more Ca ions in the system, which assisted retardation of acid attack. The third paper attempted to address the fire resistance issue of conventional cement by introduction of the geopolymer as an alternative. The fire resistance and mechanical tests were carried out on geopolymer concrete made of class $\mathrm{F}$ fly ash and ground-granulated blast furnace slag and compared to normal concrete made of ordinary Portland cement (OPC). With the proposed formula, geopolymer concrete was less fire resistant than OPC concrete because of its higher shrinkage. The results showed the limitation of starting materials containing high alkali contents. However, the issue has to be deeply investigated for more understanding of the fire-resistant geopolymer. The fourth paper proposed the use of SCMs such as natural zeolite in concrete mix. It was worth to note here that zeolite, a kind of the porous material, could improve mechanical properties of concrete in the long term due to its pozzolanic reaction. The fifth paper described hydration of OPC in the presence of various powders such as glass powder, limestone powder, and steel slag powder. They behaved differently when met with OPC in that glass powder consumed calcium hydroxide $(\mathrm{CH})$ due to its pozzolanic reaction, while limestone and steel slag powder did not react with $\mathrm{CH}$ and provided more $\mathrm{CH}$ for the system, respectively.

The sixth paper addressed the feasibility of natural rock, a kind of inert material, to synthesize the alkali-activated binder. This paper showed a successful case for using silicate minerals in groups of inosilicate and tectosilicate to produce 
the geopolymeric binder. The seventh paper addressed the utilization of autoclaved aerated lightweight concrete wastes as an aggregate in concrete mix, aiming strength improvement by internal curing. The experiments provided positive results in introduction of such wastes for concrete mix as they could supply additional water for internal curing. The eighth paper proposed new direction of cementitious materials for energy storage due to their ionic and highly porous characteristics. The challenging perspective of this cement-based battery is how to improve its power output and service life. The ninth paper addressed the difficulty in strength and durability improvements of cement paste backfill for environmental cleaning-up, especially solidification of heavy metals in fine tailings containing sulphide from zinc mine. A use of calcined kaolin for cement replacement gave positive results both in short and long terms in aspects of strength and durability. The release of toxic elements shall be further investigated to confirm the potential of solidification. The tenth paper investigated an impact of glass waste aggregate contents on mechanical properties of concrete, especially fracture parameters, aiming to promote waste utilization for construction industry. In a replacement of the natural fine aggregate, a use of glass cullet provided negative effect on fracture behavior.

The eleventh paper addressed the problem of air leakage to improve coal mining safety. This paper offered a kind of new and affordable airtight filling material which composed various kinds of cementing materials. The best recipe for sealing composed of high amount of sulfoaluminate cement due to its highly expansive behavior and fast strength development. The twelfth paper proposed the possibility for a use of very fine steatite powder as cement replacement in self-compacting concrete. This paper showed that the natural clay mineral was possible to work as a supplementary cementing material. The thirteenth paper promoted a use of high-volume fly ash in concrete in structural application such as column. It showed a good sign to adopt high-volume fly ash for construction. The fourteenth paper described the modification of hydration of Portland cement in the presence of nano- $\mathrm{SiO}_{2}$-polycarboxylate compounds which were combinations of pozzolan and superplasticizer. This paper achieved the introduction of this new composite material for controlling hydration of Portland cement. The fifteenth paper proposed the mechanical properties of alkali-activated slag concrete compared to those of Portland cement concrete. The flexural and shear behaviors of reinforced slag concrete were not significantly different from those of conventional Portland concrete. The last paper achieved the utilization of palm oil fuel ash for Portland cement replacement in terms of water permeability and chloride resistance.

$$
\begin{array}{r}
\text { K. Pimraksa } \\
\text { P. Chindaprasirt } \\
\text { J. Sanjayan } \\
\text { T.-C. Ling }
\end{array}
$$




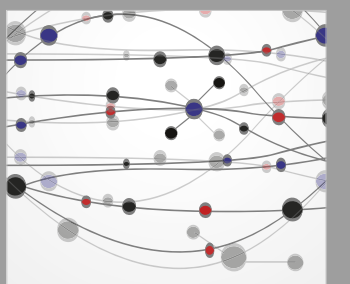

The Scientific World Journal
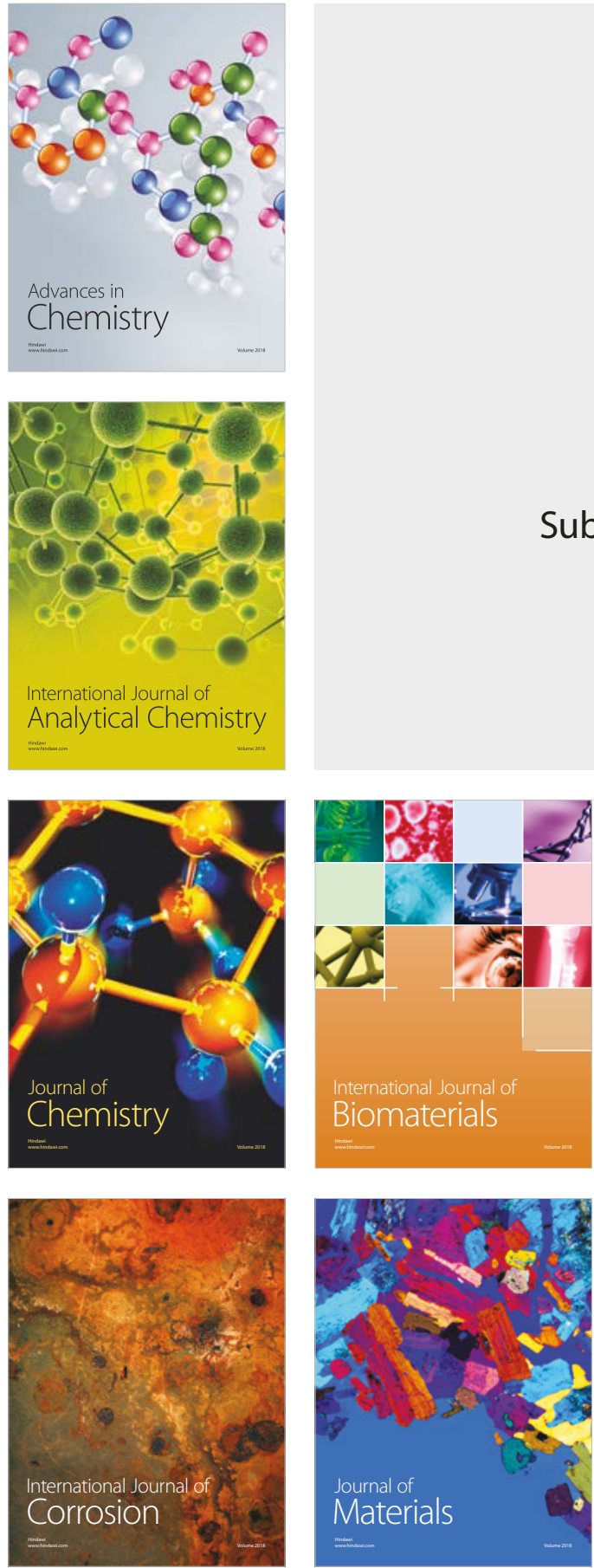

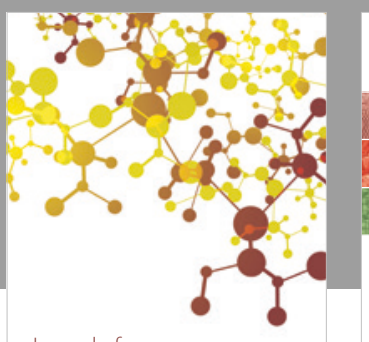

Journal of

Applied Chemistry
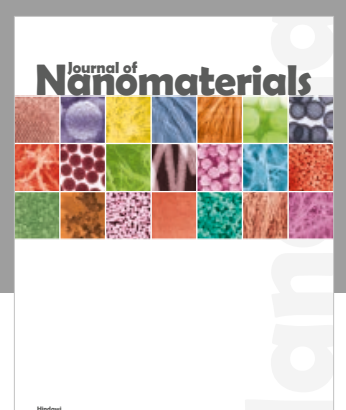

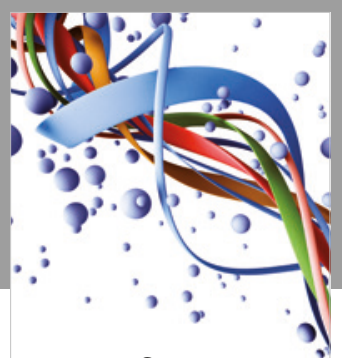

Scientifica

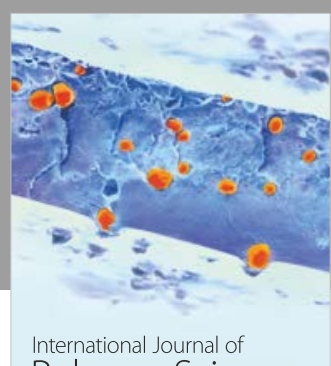

Polymer Science

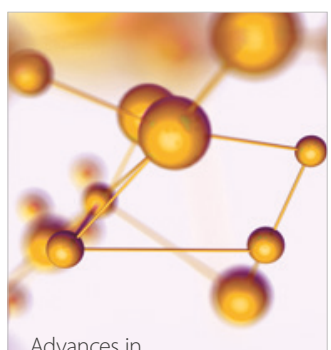

Physical Chemistry
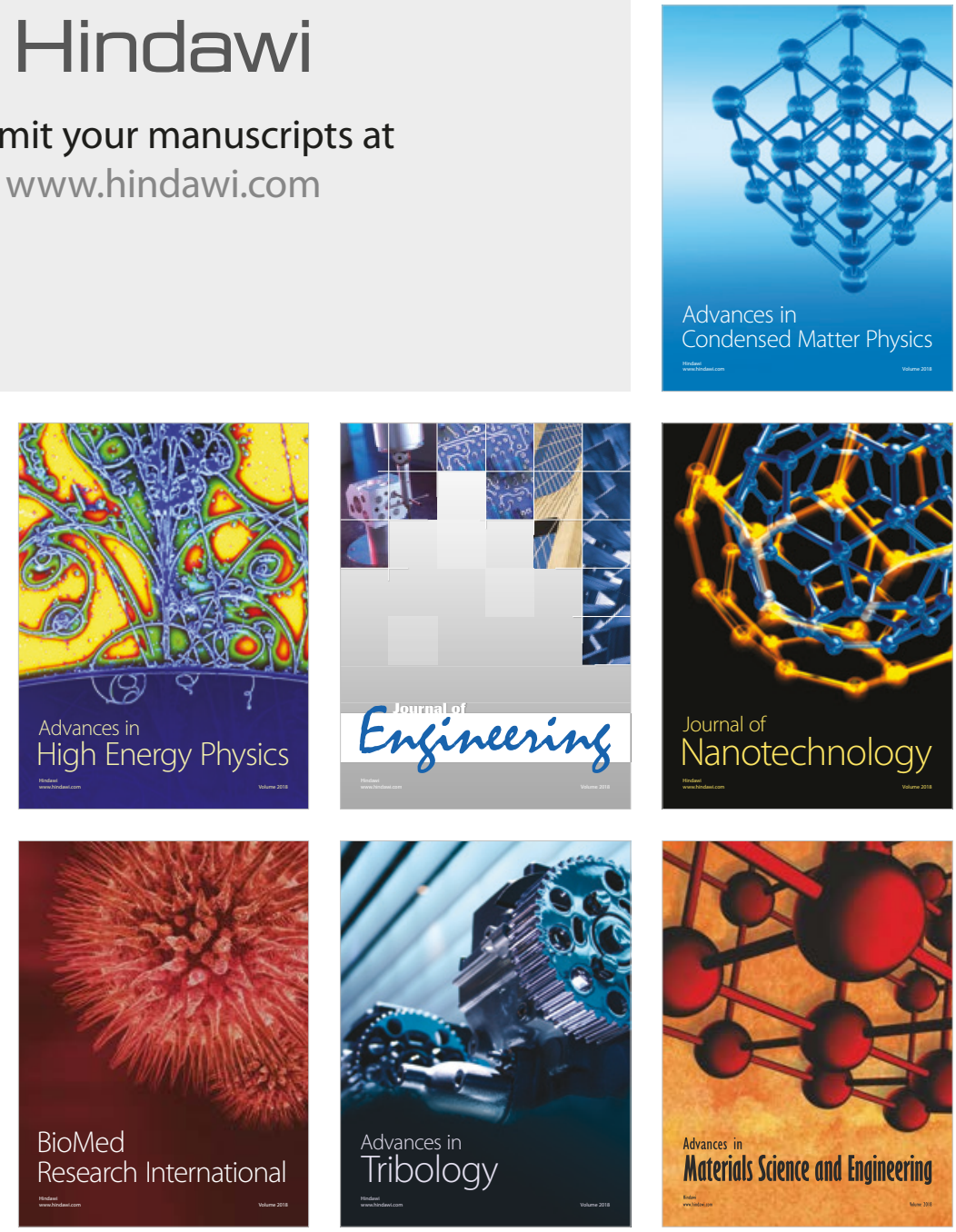